\title{
EL GÉNERO DEL DOCUMENTAL INTERACTIVO COMO EXPERIENCIA ARTÍSTICA-CREATIVA DE EMPODERAMIENTO JUVENIL: EL CASO DEL WEBDOC HEBE
}

THE INTERACTIVE DOCUMENTARY AS A CREATIVE AND ARTISTIC EXPERIENCE FOR YOUTH EMPOWERMENT: THE HEBE WEBDOC AS A CASE OF STUDY

O GÉNERO DO DOCUMENTÁRIO INTERATIVO COMO EXPERIÊNCIA ARTÍSTICA-CRIATIVA DE CAPACITAÇÃO JUVENIL: O CASO DO WEBDOC HEBE

\author{
Alan SALVADÓ ROMERO, Manel JIMÉNEZ-MORALES \& Carolina SOURDIS \\ Universitat Pompeu Fabra
}

Fecha de recepción del artículo: 27.11.2017

Fecha de revisión del artículo: 15.111.2017

Fecha de aceptación final: 15.V.2017

PALABRAS CLAVES: empoderamiento juventud webdoc pedagogía artística ciencia ciudadana
RESUMEN: Las posibilidades de interacción que ofrecen las nuevas tecnologías abren posibilidades inéditas tanto para la investigación del empoderamiento juvenil en el seno de la academia, como para el el diseño e implementación de metodologías participativas que favorezcan los procesos de empoderamiento de los jóvenes en la sociedad. El webdoc HEBE [www.hebewebdoc.com] que describimos en este artículo se presenta como un caso pionero en el terreno del empoderamiento juvenil por el hecho de aunar en una única plataforma interactiva relatos de empoderamiento concebidos como piezas audiovisuales, reflexiones sobre el proceso de creación a través de distintos focus group y, finalmente, la posibilidad de compartir digitalmente estos materiales audiovisuales para hacerlos dialogar con la ciudadanía. En la primera parte del artículo se detallan y analizan los tres factores principales que están en la base del webdoc HEBE: la evolución de las metodologías participativas de empoderamiento basadas en la creación audiovisual, la utilización de nuevos soportes transmediáticos que permiten la participación colectiva y, por último, la consolidación de una pedagogía del cine como vía de aprendizaje de una experiencia vital y emocional. En la segunda parte se detallan las fases del proceso de construcción del webdoc HEBE, profundizando en los aspectos más relevantes y exponiendo sus cualidades como herramienta de ciencia ciudadana. También se explica la metodología pedagógica aplicada en el taller de creación y el diseño de la página de navegación del webdoc que implica la construcción de narrativas que permitan al usuario 


\begin{tabular}{|c|c|}
\hline & $\begin{array}{l}\text { reflexionar sobre los procesos, espacios y momentos de empoderamiento juvenil. Finalmente, } \\
\text { en la tercera parte, se presentan los primeros resultados derivados de la finalización del dise- } \\
\text { ño del webdoc como plataforma, a partir del análisis de las piezas resultantes, realizadas por } \\
\text { los participantes del taller de pedagogía audiovisual. }\end{array}$ \\
\hline $\begin{array}{l}\text { KEY WORDS: } \\
\text { empowerment } \\
\text { youth } \\
\text { webdoc } \\
\text { artistic pedagogy } \\
\text { citizen science }\end{array}$ & $\begin{array}{l}\text { ABSTRACT: The interaction potential offered by new technologies open up unprecedented } \\
\text { possibilities both for the investigation of youth empowerment within academia, and for the } \\
\text { design and implementation of participatory methodologies that foster young people's em- } \\
\text { powerment processes in society. The HEBE webdoc [www.hebewebdoc.com] described in } \\
\text { this paper is presented as a pioneering case in the field of youth empowerment, as it com- } \\
\text { bines within a single interactive platform: empowering stories in the form of audiovisual seg- } \\
\text { ments; reflections on the creative process as shown in various focus groups; and, finally, digital } \\
\text { sharing in order to enable a dialogue between the materials and citizens. } \\
\text { The first section provides details of and analyzes the three main factors on which the } \\
\text { HEBE webdoc is based: the evolution of empowerment participatory methodologies based } \\
\text { on audiovisual creation; the use of new transmedia formats that allow collective participation; } \\
\text { and the establishment of a film pedagogy as a way to learn from an emotional life experience. } \\
\text { The second section describes the stages of the HEBE webdoc building process, by de- } \\
\text { tailing the most important aspects and revealing its qualities as a tool for citizen science. It } \\
\text { also explains the pedagogical methodology applied in the workshop where it was created, and } \\
\text { the webdoc site's navigation layout, which involves the construction of narratives that enable } \\
\text { the user to reflect on processes, spaces and youth empowerment moments. } \\
\text { To conclude, the third section contains the initial results from the completed webdoc's } \\
\text { platform design, based on an analysis of the pieces resulting from the audiovisual education } \\
\text { workshop, carried out by the participants. }\end{array}$ \\
\hline $\begin{array}{l}\text { PALAVRAS-CHAVE: } \\
\text { capacitação } \\
\text { juventude } \\
\text { webdoc } \\
\text { pedagogia artística } \\
\text { ciência da cidadania }\end{array}$ & $\begin{array}{l}\text { RESUMO: As possibilidades de interação que as novas tecnologias oferecem abrem possibi- } \\
\text { lidades inéditas, tanto para a investigação da capacitação juvenil no seio da academia, como } \\
\text { para a conceção e implementação de metodologias participativas que favoreçam os proces- } \\
\text { sos de capacitação dos jovens na sociedade. O webdoc HEBE [www.hebewebdoc.com] que } \\
\text { descrevemos neste artigo apresenta-se como um caso pioneiro no terreno da capacitação } \\
\text { juvenil pelo facto de reunir, numa única plataforma interativa, relatos de capacitação conce- } \\
\text { bidos como peças audiovisuais, reflexões sobre o processo de criação através de diferentes } \\
\text { focus group e, por fim, a possibilidade de partilhar digitalmente estes materiais audiovisuais } \\
\text { para os fazer dialogar com a cidadania. Na primeira parte do artigo, detalham-se e analisam-se } \\
\text { os três fatores principais que estão na base do webdoc HEBE: a evolução das metodologias } \\
\text { participativas de capacitação baseadas na criação audiovisual, a utilização de novos suportes } \\
\text { transmediáticos que permitem a participação coletiva e, por último, a consolidação de uma } \\
\text { pedagogia do cinema como via de aprendizagem de uma experiência vital e emocional.Na } \\
\text { segunda parte, detalham-se as fases do processo de criação do webdoc HEBE, aprofundando } \\
\text { os aspetos mais relevantes e expondo as suas qualidades como ferramenta de ciência da ci- } \\
\text { dadania. Também se explica a metodologia aplicada na oficina de criação e o design da página } \\
\text { de navegação do webdoc, que implica a criação de narrativas que permitam ao utilizador } \\
\text { refletir sobre os processos, espaços e momentos de capacitação juvenil. Por fim, na terceira } \\
\text { parte, apresentam-se os primeiros resultados derivados da finalização do design do webdoc } \\
\text { como plataforma, a partir da análise das peças resultantes, realizadas pelos participantes da } \\
\text { oficina de pedagogia audiovisual. }\end{array}$ \\
\hline
\end{tabular}

\section{Introducción}

El webdoc HEBE [www.hebewebdoc.com], que presentamos como estudio de caso en este artículo, forma parte de una investigación más amplia ("Proyecto-HEBE: El empoderamiento de los jóvenes: análisis de los momentos, espacios y procesos que contribuyen al empoderamiento juvenil" [2013-2017]) en la que participan las universidades de Girona (UdG), Barcelona (UB), la Autónoma de Barcelona (UAB) y la Pompeu Fabra (UPF). El objetivo principal de dicha investigación es identificar y analizar los momentos, espacios y procesos de empoderamiento juvenil a partir de tres líneas de investigación: los relatos de vida de una muestra representativa de jóvenes, la evaluación participativa a partir de un cuestionario $y$, finalmente, la realización de un documental interactivo como herramienta de análisis y reflexión sobre el empoderamiento juvenil. Bajo este objetivo se pretende explorar la conceptualización del término empoderamiento desde el desarrollo práctico de una experiencia auto-reflexiva y de capacitación. Es precisamente esta última línea, liderada por la Universidad Pompeu Fabra, la que queremos detallar y desarrollar en el presente artículo, intentando satisfacer un asunto candente y oportuno dentro de la Pedagogía Social por su capacidad de abordar una posible metodología que permita sumar al crecimiento de las políticas de inserción 
y capacitación de los jóvenes en la sociedad. Profundizaremos, por un lado, en aquellos aspectos y fases del proceso de concepción y realización del webdoc que se contemplan como método, y por el otro, pondremos de relieve sus potencialidades como herramienta de investigación sobre el empoderamiento juvenil, para plantear nuevas dinámicas de participación y vías de capacitación para los jóvenes. Esta es la hipótesis principal de la investigación: se parte de la premisa de que el documental interactivo sirve a la finalidad de autonarrarse y así contribuir a la definición del concepto "empoderamiento"; además se considera que la producción de este género bajo los planteamientos del Proyecto-HEBE es, en sí misma, una experiencia empoderadora. Las posibilidades de interacción y la facilidad de diseminación de los contenidos a través de las redes sociales convierten la iniciativa en un instrumento que por la vía artístico-creativa invita a una reflexión sobre las formas de empoderamiento de los jóvenes.

"Webdoc" es el término más utilizado para referirnos a los documentales interactivos, pero bajo esta terminología se engloban varios formatos y contextos (Català, 2010): desde el reportaje periodístico al discurso audiovisual experimental o al transmedial que acompaña un producto realizado para la televisión (Sora, 2015). La creación de webdocs vive un gran momento de eclosión, sin aún tener unos patrones claros de diseño ni de uso. A pesar de ello, y aunque el webdoc no es un concepto ni un formato nuevo, las posibilidades de interacción que ofrece este género en el contexto transmediático actual hacen de él, una herramienta original y singular para la investigación y reflexión sobre el empoderamiento juvenil.

La hibridación del tradicional género documental, definido por Bill Nichols (1991) a partir de su capacidad de representar la realidad, junto con la posibilidad de la narración interactiva, acerca el término "webdoc" al concepto contemporáneo de las vídeo instalaciones o multi-pantallas. Este aspecto implica que el montaje descriptivo y lineal característico del documental desaparece para plantear un tipo de montaje reflexivo y no-lineal donde las preguntas e inquietudes del usuario son las que determinan el avance en el relato. Como apunta Arnau Gifreu "en el formato del documental web se da paso a formulaciones para-táxicas (de simple yuxtaposición) que, a pesar de su aparente simplicidad, son la antesala de arquitecturas constelación relativas no lineales mejor preparadas para la complejidad. De esta manera, el fundamento ontológico de la fotografía se combina con otros elementos post-fotográficos para delimitar el régimen de una nueva post-visión de carácter reflexivo en la que intervienen de manera primordial los mecanismos de la imaginación documental" (Gifreu, 2013). Como podemos observar, pues, el propio proceso de interacción a través del webdoc se plantea como un proceso creativo donde el usuario debe establecer él mismo un diálogo con las distintas partes que compongan el documental. Para sintetizar, pues, podemos determinar que las características del documental interactivo que nos llevan en el contexto del Proyecto-HEBE a trabajar en este género/soporte quedan definidas por Peter Wintonick: "Docmedia take the complexities of conventional documentary and fuse them to the best qualities of new media. The playing with time. The responsibility to audiences. The Documentary as Database. Interactivity. The One to One and Many to Many. Real Truth, a million page-hits a second. Webdocs are new informational art forms" (Wintonick, 2011, citado por Gifreu, 2013:274).

En la base del webdoc HEBE convergen tres factores de relevancia que detallaremos más adelante: (1) los estudios recientes alrededor del empoderamiento juvenil $y$, más concretamente, las iniciativas participativas realizadas entre grupos de jóvenes como mecanismo de empoderamiento para hacer frente a determinadas problemáticas sociales; (2) la proliferación de narrativas transmediáticas y no lineales que utilizan el desarrollo de la industria de los medios (nuevas plataformas y dispositivos de consumo audiovisual) para situar la interacción y participación del usuario en el centro de la acción; y por último, (3) la creciente incorporación de la práctica audiovisual como estrategia pedagógica y de educación emocional hacia los jóvenes, como el caso de experiencias exitosas a nivel nacional como Cine en curso': programa de pedagogía del cine y con el cine en escuelas e institutos, "nacido del deseo y la urgencia de generar un descubrimiento activo y profundo por parte de niños y jóvenes del cine como arte y creación" (Aidelman \& Colell, 2014; p. 25).

Como resultado de la imbricación de estos tres factores, el webdoc se ha diseñado como una plataforma para navegar a través de dos tipos de registro: por un lado, 3 piezas audiovisuales cuyo hilo conductor son los espacios, procesos y momentos de empoderamiento juvenil, realizadas por 6 jóvenes entre 18 y 27 años, tras un taller de formación en audiovisual diseñado por el grupo de investigación, y una reflexión de los jóvenes sobre sus procesos particulares de empoderamiento, guiada por los indicadores de la investigación global. Estas piezas constituyen la columna vertebral del webdoc, ya que sintetizan el proceso de aprendizaje de los jóvenes, y reflexionan sobre la experiencia de empoderamiento personal de cada uno en sus diferentes contextos. Por otra 
parte, el webdoc presenta una serie de discusiones filmadas a modo de focus-group, donde tanto expertos y profesionales en políticas e iniciativas de juventud, como los jóvenes participantes del taller, reflexionan en torno al empoderamiento: los primeros, procurando conceptualizar el término desde los indicadores y alcances de la investigación macro (Proyecto-HEBE) desde la perspectiva de las piezas audiovisuales de los jóvenes, y los segundos, desde su propia experiencia de aprendizaje. La interfaz o página de navegación permite al usuario del webdoc poner en relación y retroalimentación ambas perspectivas: un proceso de aprendizaje en torno a la creación y al desarrollo de competencias comunicativas vivido por 6 jóvenes de contextos diferentes, y la visión más teórica y experta que analiza en profundidad las inquietudes, deseos y problemáticas que los jóvenes han plasmado en sus piezas.

Por último, considerando la facilidad de participación que ofrecen las plataformas virtuales, el webdoc abre un espacio para que los diferentes usuarios puedan añadir contenido y contribuir a la conceptualización del término de empoderamiento: pueden incluir comentarios, reflexiones o imágenes de su propia experiencia como ciudadanos a través de la red social twitter, contribuyendo a la creación de redes entre jóvenes y expertos. A lo que apunta esta posibilidad de interacción es a fomentar que la ciudadanía tome una participación activa en la creación de sus contenidos y así completar una dinámica de pedagogía artística donde se cruzan la educación social con la emocional. Así pues, HEBE aúna a través de un formato interactivo un proceso didáctico de empoderamiento a través de la creación, junto con las iniciativas y reflexiones teóricas en torno al concepto de empoderamiento juvenil, posibilitando el vínculo entre academia y ciudadanía. Sin lugar a dudas, la convergencia de los medios replantea la forma en cómo se pueden articular determinadas iniciativas focalizadas en el empoderamiento juvenil en un contexto marcado por una profunda crisis económica (donde los jóvenes son los principales perjudicados) y la progresiva consolidación de los entornos transmediáticos (cuyos principales usuarios son los jóvenes).

Finalmente, cabe aclarar que entendemos el concepto de "empoderamiento" como "el proceso mediante el cual se incrementan las posibilidades de que una persona pueda decidir y actuar de forma consecuente sobre todo aquello que afecta a su propia vida; y participar en la toma de decisiones e intervenir de forma compartida y responsable en lo que afecta a la colectividad de la que forma parte. Para que todo ello pueda producirse son necesarias dos condiciones: que la persona vaya adquiriendo y desarrollando una serie de capacidades personales (conocimientos, actitudes, aptitudes, destrezas...) directamente relacionadas con lo anterior; y que el medio le facilite ejercer efectivamente tales capacidades" (Soler, Trilla, Úcar \& Jiménez; 2017). Bajo esta acepción se concibe el presente estudio de caso.

\subsection{Antecedentes de metodologías participativas sobre empoderamiento juvenil}

La producción científica alrededor de la utilización de determinados media como mecanismos de empoderamiento juvenil ha incrementado en los últimos años. La mayor parte se ha focalizado en la descripción de experiencias prácticas realizadas con grupos de jóvenes (a veces incluso adolescentes) inmersos en determinadas dificultades sociales. En todas ellas, la expresión de los jóvenes a través de distintos medios, como la radio (Wagg, 2004), la fotografía (Delgado, 2015), el vídeo (Haynes \& Tanner, 2013; el proyecto internacional YouthME $\left.{ }^{2}, 2013\right)$ o el cine documental (Cohen, 2016), es el hilo conductor para identificar las problemáticas concretas sobre las cuales tomar conciencia para, posteriormente, tratar de llevar a cabo medidas directas o indirectas.

En el terreno de la Pedagogía Social, la metodología participativa usada con más éxito y frecuencia (principalmente en el mundo anglosajón) ha sido el Photovoice (Wang, 2006). Esta técnica se articula a partir de un doble proceso: encuadrar visualmente (a través de las fotografías tomadas por los participantes a lo largo de su día a día) una determinada problemática social para, posteriormente, dar voz a una reflexión en grupo sobre las imágenes que la representan; podríamos resumirlo como el proceso de visualizar, verbalizar y, finalmente, reaccionar. Su naturaleza inclusiva y su adaptabilidad entre grupos culturales distintos ha permitido llevar a cabo experiencias para dar voz a determinados colectivos y promover cambios en el centro de una comunidad, como la erradicación de la violencia juvenil (Wang, Morrel-Samuels, Hutchison, Bell \& Pestrong, 2004), la integración social de minorías raciales (Pritzker, LaChapelle \& Tatum, 2012) o bien la prevención del crimen (Ohmer \& Owens, 2013). Dichas experiencias sitúan la capacitación a través de las imágenes en el eje central de su planteamiento, convirtiendo la fotografía en una herramienta, tanto de empoderamiento para los jóvenes, como de investigación acerca del propio empoderamiento por parte de la academia.

Otro caso paradigmático y referente para nuestro webdoc es el proyecto de empoderamiento e investigación YES!, destinado a preadolescentes desfavorecidos (de entre 9 a 12 años) 
y realizado en escuelas de primaria y secundaria (Wilson et al, 2007). En él se utiliza, en una primera fase, el Photovoice para implicar a los jóvenes en el cambio de problemáticas sociales, reflexionando a partir de fotografías sobre una serie de preguntas clave: 1) ¿Qué ves aquí?; 2) ¿Qué está pasando realmente?; 3) ¿Cómo se relaciona esto con nuestras vidas?; 4) ¿Por qué existe este problema o esta calidad?; y 5) ¿Qué podemos hacer? A la técnica del Photovoice le sucede la técnica del Reflect-Acción (2009) donde se forman grupos entre los participantes cuya finalidad es reflexionar, hacer un diálogo crítico y clasificar la importancia de las cuestiones que se desprenden de las imágenes. Todo ello se realiza en lo que podríamos denominar "espacios democráticos y de libre expresión" que reproducen la voluntad de adquisición de poder con la finalidad de implicar al grupo en el desarrollo de un proyecto de acción social. La función de aprendizaje-servicio que aquí se desempeña permite propiciar el cambio de la acción sobre el entorno a través de un ejercicio de autor-reflexión. A partir de lo apuntado, observamos que la singularidad del proyecto YES! es que los principios del empoderamiento juvenil se desarrollan tanto desde una perspectiva individual como comunitaria.

Ambos ejemplos, a los que podríamos añadir otros de planteamientos y estructuras similares (Finholdt, Michael, \& Davis, 2010; Foster-Fishman, Law, Lichty, \& Aoun, 2010; Strack, Magill, \& McDonagh, 2004; Streng et al., 2004) ilustran las pautas fundamentales de la metodología del Photovoice, descritas por Wang \& Burris (1997), que pasan por: (1) la selección de un grupo de participantes, (2) la proposición de un tema específico para trabajar conjuntamente en talleres grupales; (3) el proporcionar a los jóvenes las cámaras para retratar su realidad; (4) el reflexionar sobre las imágenes; y finalmente, (5) el compartir las imágenes y las reflexiones con responsables de los distintos agentes sociales.

En el origen del webdoc HEBE situamos, pues, las fases estándares de la metodología del Photovoice para introducir una variante en la última fase del proceso: el compartir las imágenes. El soporte interactivo del webdoc permite que la acción de compartir las experiencias de empoderamiento trascienda también a la ciudadanía que deviene un agente activo capaz de tener voz para visualizar y verbalizar su propia experiencia de empoderamiento. La cultura participativa implícita en los entornos transmediáticos añade una fase en el proceso de empoderamiento del Photovoice.

\subsection{Cultura participativa y ciencia ciudadana: bases del webdoc HEBE}

El segundo factor que nos ha llevado a acercarnos al formato del documental interactivo ha sido la voluntad de incorporar la ciencia ciudadana (Irwin, 1995) para el desarrollo de la investigación, basándonos en autores como Ulf-Dietrich Reips \& Michael Bosnjak (2011) o Kevin Gurney (Ventus Project, 2013), entre otros. Dada la facilidad de participación y diseminación de contenidos, hemos considerado las nuevas plataformas digitales (Gifreu; 2012) y las redes sociales (Ito et al.; 2013), y su potencialidad para crear redes virtuales de comunicación entre la ciudadanía, como las herramientas más adecuadas para difundir los resultados de la investigación y, al mismo tiempo, obtener el relato de los jóvenes sobre sus propias experiencias de empoderamiento. Siguiendo las argumentaciones de Lloret y Canet, las posibilidades de interacción del llamado "moviento 2.0" permiten que el consumidor se convierta en un generador de contenidos y propicie la generación de comunidades que se retroalimentan desde la subjetividad y el desarrollo individual, permitiendo la construcción de comunidades más allá de las fronteras geográficas (2008). Esto es fundamental para la investigación, dado que para englobar un concepto de empoderamiento juvenil es importante la valoración de experiencias subjetivas mediadas por comunidades de distintos contextos. Tal y como apuntan Lloret y Canet, las dinámicas del llamado movimiento Web 2.0 permiten movilizar colectivos. De un lado, porque las nuevas aplicaciones permiten al usuario convertirse en creador y consumidor de contenidos según sus propias y particulares necesidades, pero, por otro lado, porque le permite integrar e integrarse en comunidades que comparten gustos, necesidades, sueños, sentimientos y experiencias, de una forma que ya no depende de fronteras espaciales o temporales, generando el ambiente adecuado para una producción y consumo de conocimiento socialmente distribuido, pero a la vez para un usufructo personal, desde los intereses particulares; es decir, no se trata de comunidades, donde el colectivo disuelve la subjetividad, sino de comunidades que favorecen y a la vez legitiman y necesitan del crecimiento de cada sujeto, mediante la gestión de cada individualidad". (Lloret \& Canet; 2008, p. 2)

La experiencia de empoderamiento individual compartida y, a la vez, confrontada a la comunidad, por tanto, es uno de los ejes centrales del webdoc HEBE. Por este motivo, y para que el recorrido entre la individualidad y la comunidad sea continuo, el webdoc no debe cerrarse en sí 
mismo: debe entenderse como un relato abierto y dinámico donde los usuarios (la ciudadanía) puedan prolongar y completar las experiencias de empoderamiento individual. En el centro de la cuestión reside una de las claves de las narrativas transmediáticas (Scolari, 2013): los relatos se expanden, han dejado de ser conclusivos y pensados únicamente desde una individualidad. En este sentido, nuestro objetivo con el uso del género del webdoc es el de convertir HEBE en una herramienta de uso, fácilmente apropiable para la ciudadanía, tanto por parte de entidades y asociaciones que trabajan con jóvenes como por parte de los responsables de políticas de juventud. Así pues, las palabras de David Casacuberta son muy descriptivas del espíritu de nuestro proyecto: "las obras culturales de la cultura digital ya no se construyen en forma individual, solipsista, sino de forma colectiva, organizada. El artista deja de ser creador estricto para convertirse en productor. El artista desarrolla una herramienta que luego será el público el que la use, desarrolle y difunda según sus intereses, que no tienen porque coincidir ni estar influenciados por la voluntad original del artista... El trabajo del artista es literalmente el de un médium: ofrecer una estructura, una herramienta, un medio en el que sea el espectador el que se exprese, en el que sea el espectador el que cree". (2003; p. 60-61)

En el contexto de las narrativas transmediáticas, el concepto teorizado por Henry Jenkins de "cultura participativa" es fundamental para enmarcar el objetivo del webdoc. Dice Jenkins, "a participatory culture is one which embraces the values of diversity and democracy through every aspect of our interactions with each other -one which assumes that we are capable of making decisions, collectively and individually, and that we should have the capacity to express ourselves through a broad range of different forms and practices". (2016; p. 2). La reflexión de Jenkins se aplica al fenómeno fandom, por el cual las comunidades de fans de determinados productos audiovisuales (series, sagas o films de género) no solo devienen consumidores sino también productores de contenidos. Nacido del análisis de las comunidades de fans (Jenkins; 1992), propensas al uso de las nuevas plataformas mediáticas y a las prácticas y experiencias de creaciones audiovisuales, la cultura participativa de Jenkins puede aplicarse en otro tipo de comunidades y/o entornos tal y como él mismo indica: "fans were simply one among many different kinds of communities that had been struggling throughout the twentieth century to gain greater access to the means of cultural production and circulation". (2016; p. 3). Partiendo de estos planteamientos el webdoc
HEBE pretendía, tanto en su concepción como en su despliegue, poner el foco de atención en la cuestión de la cultura participativa aplicada a la reflexión alrededor del empoderamiento. En última instancia, y también es destacado por parte del propio Jenkins, la cultura participativa es una herramienta con un enorme potencial pedagógico. "A participatory culture is a culture with relatively low barriers to artistic expression and civic engagement, strong support for creating and sharing one's creations, and some type of informal mentorship whereby what is known by the most experienced is passed along to novices. A participatory culture is also one in which members believe their contributions matter, and feel some degree of social connection with one another (at the least they care what other people think about what they have created)". (2016; p. 4)

En resumen, la idea de implicar a la ciudadanía en el progreso y la difusión de la ciencia ha llevado a plantearnos el formato interactivo del webdoc como el más idóneo para el desarrollo de nuestra investigación acerca del empoderamiento juvenil. Un hecho que por otra parte, ha permitido trasladar al formato audiovisual las técnicas tradicionales de los relatos de vida o los focus group. La adaptación de las tradicionales metodologías de investigación a los nuevos soportes interactivos ha sido, pues, uno de los principales objetivos de esta línea de investigación del Proyecto-HEBE.

\subsection{Un proceso artístico de empoderamiento a partir del aprendizaje del cine}

El tercer factor que está en la base del webdoc HEBE es la aproximación al proceso de aprendizaje desde la dimensión artística y creativa que explora la iniciativa. A diferencia de las experiencias mencionadas del Photovoice, donde la fotografía adquiere un carácter instrumental para identificar determinadas problemáticas sociales, nuestro objetivo es el de incorporar activamente el proceso artístico y creativo a través del audiovisual como una vía para expresar, de forma íntima y personal, las experiencias de empoderamiento de los jóvenes, convirtiendo así la plataforma del webdoc en un espacio para compartir experiencias y problemáticas individuales concebidas a partir de determinados indicadores de empoderamiento. Para este fin se ha diseñado un taller de pedagogía audiovisual, entendido como un seminario de lenguaje fílmico y educación emocional que tiene como hilo conductor dos componentes fundamentales: (1) sensibilización en torno a la imagen fílmica; (2) reflexión sobre procesos individuales de empoderamiento en relación al recorrido vital de los participantes. Por un lado, el primer 
componente tiene como objetivo aprender a leer y desarrollar una sensibilidad que permita interpelar a las imágenes fílmicas y a la vez dejar que ellas interpelen nuestra sensibilidad, observando y cuestionando las elecciones formales de los cineastas e intentando vincular esta mirada activa para hacer una evaluación del entorno con miras a la creación. Identificar las emociones que suscitan ciertas imágenes es una forma de conectar con la sensibilidad de uno mismo, racionalizar emociones y por tanto tener otros lugares desde donde interpretar la propia experiencia. Por otro lado, el segundo componente tiene como objetivo permitir que los participantes tracen su propia línea vital para identificar cuáles han sido los procesos de empoderamientos, las acciones y contextos que los han llevado a constituirse como individuos. A partir de aquí, cada uno debe concebir el contenido de sus piezas fílmicas.

La metodología de sensibilización en torno a la imagen fílmica está fundada en el proyecto pedagógico del cineasta, profesor y pedagogo francés Alain Bergala, creador de la inciativa de la Cinemateca Francesa Le Cinéma, cent ans de jeunesse (2009-2017), e inspirador y referente de otras inciativas en torno a la pedagogía filmica, entre ellas la ya antes referida Cinema en Curs.

Entre los años 2000 y 2003, Bergala fue consejero sobre cine para el "Plan de cinco años para el desarrollo de las artes y de la cultura en la escuela", impulsado por los Ministerios de Cultura y Educación en Francia. El espíritu del proyecto pedagógico se expone en el libro La hipótesis del cine (2007). Bajo estos preceptos, y sintetizando de forma extrema las reflexiones de Alain Bergala, uno de los principales objetivos de la enseñanza del cine debe ser el de provocar un encuentro con la alteridad, con aquello alejado de la regla y que ayude al estudiante/espectador a iniciarse en el sinuoso camino del arte cinematográfico. No se trata de formar sino transmitir una experiencia o una vivencia que favorezca el proceso de iniciación a las imágenes cinematográficas; es decir, educar la mirada del espectador para que pueda encontrarse con el cine y la creación. Es por esto que Bergala considera que más que enseñar y privilegiar los aspectos lingüísticos del cine (tipos de planos, formas de escribir un guión, aspectos técnicos de la luz o el sonido), lo importante es favorecer un acercamiento a él desde la sensibilidad, para así contemplarlo como el resultado de un proceso creativo que ha estado sujeto a múltiples avatares. $\mathrm{O}$ lo que es lo mismo, comprender que no pueden existir dogmas cuando el objetivo de la práctica cinematográfica es el de dar forma a unas determinadas emociones. Tal y como apunta Alain Bergala, "en una escuela de cine, las "normas" y lo "profesional" son una amenaza. A menudo pregunto a los alumnos por qué su filme es tan plano, o por qué las mezclas son de una determinada manera; casi siempre responden "porque lo queremos hacer bien". Ahí está el peligro: todo el mundo quiere "hacerlo bien", todos quieren "ser buenos". El cineasta puede pedir una imagen pobre, pero el director de fotografía se resiste. El peligro permanente es el academicismo. La creación es otra cosa". (2014; p. 16). La experiencia fílmica y su aprendizaje se entienden, pues, como un ejercicio de creación no ceñido a unas pautas de excelencia, sino motivado por la voluntad expresiva y emocional del que lo crea. No hay resultados buenos o malos, hay simplemente comunicación de los sentimientos.

Teniendo en cuenta la premisa de Bergala, compartida por muchos otros autores (Langlois, 1986; Comolli, 2007), el enfoque del taller HEBE no está encaminado a la formación técnica específica del audiovisual, sino a despertar una sensibilidad que permita la expresión de emociones y reflexiones derivadas de las experiencias personales de empoderamiento. Así pues, con el objetivo de que la técnica no fuera un impedimento a la expresión individual de los participantes del taller, un cineasta-profesor les acompañaba a lo largo de todo el proceso, desde la ideación de la pieza, pasando por el rodaje, hasta su edición. El hecho de que el tutor o acompañante esté ahí no significa que tenga que intervenir, todo lo contrario. Tal y como apuntan Núria Aidelman y Laia Colell sobre la metodología Cine en curso, "concebimos el cine como poética y, en tanto que poiesis, como un medio y un modo de conocimiento, pensamiento, emoción, asombro, interrogación sobre uno mismo, los otros y el mundo. Este principio articula todos los procesos y metodologías y, muy especialmente, el eje vertebrador de los talleres: la estrecha vinculación entre visionado y práctica, entre ver cine y hacer cine" (Aidelman \& Colell; p. 25).

Por este motivo, el proceso creativo para realizar las piezas audiovisuales sobre el empoderamiento, se traduce en un taller de 8 sesiones, donde el encuentro y discusión sobre las imágenes sea el eje conductor del proceso y no la enseñanza de la lingüística cinematográfica.

\section{Metodología}

La metodología del taller puede sintetizarse del siguiente modo: 1) visualización de fragmentos y discusión sobre las emociones que suscitan las imágenes 2) captura de imágenes de lo cotidiano desde donde se puedan empezar a estructurar las piezas finales 3) visualización conjunta de los 
planos y fotografías que cada uno va realizando a lo largo del tiempo y retroalimentación conjunta y participativa de todos los participantes 4) sesiones individuales de tutoría en relación a las inquietudes particulares de cada pieza 5) rodajes 6) montajes 7) visionado conjunto de las piezas terminadas.

Expuestos los fundamentos del webdoc HEBE detallaremos, a continuación, sus principales fases de desarrollo. Queremos destacar que en el momento de la redacción de este artículo el proyecto se encuentra en su etapa final: introducción de todos los contenidos audiovisuales en la interfaz digital y el diseño de las narrativas de interacción que deben guiar al usuario a través de los distintos materiales. Por este motivo, e inspirados por las referencias metodológicas citadas previamente, exponemos las distintas fases del proceso a la espera de poderlas contrastar y de explorar las interacciones que se den desde la plataforma para desarrollar un análisis específico de su recepción por parte de la ciudadanía. En posteriores publicaciones nos centraremos en los resultados de la aplicación de esta metodología participativa.

\subsection{Fase 1: Diseño del taller de creación audiovisual}

La primera parte del webdoc HEBE ha consistido en el diseño del taller de pedagogía audiovisual (8 sesiones a lo largo de 2 meses) basado en un concepto: el empoderamiento juvenil. El objetivo final del taller es facilitar las herramientas para la realización de tres piezas audiovisuales, por parte de cada uno de los seis participantes, que son la base estructural del webdoc. Las tres piezas audiovisuales tienen como hilo conductor el empoderamiento juvenil en relación con el punto de partida de la investigación: el análisis de los espacios, los procesos y los momentos de empoderamiento. En correspondencia con este planteamiento, las piezas audiovisuales deben consistir en: (1) el retrato fílmico de un espacio que haya sido importante en el proceso de empoderamiento del participante del proyecto; (2) el retrato de un personaje que haya incidido en el proceso de empoderamiento del participante del proyecto; y finalmente, (3) un auto-retrato a partir de los momentos de empoderamiento vividos por el participante del proyecto. Las competencias que se plantean desarrollar en este proceso parten de la concepción del empoderamiento juvenil como proceso activo y continuado (Tromp, 2007; Betancor, 2011). De modo que la formación que se ofrece en esta fase cuenta con un seguimiento sostenido en el tiempo ( 2 meses de duración del taller, desde la ideación y concepción de las piezas hasta su edición), el cual pretende desarrollar situaciones que provoquen la interactividad con los participantes y su evolución progresiva.

Las sesiones del taller están estructuradas de la siguiente manera:

a) Sesión 1. Presentación del Taller de Empoderamiento a partir de la práctica del cine. Discusión y reflexión grupal sobre momentos, espacios y procesos de empoderamiento juvenil en base a la investigación marco. Explicación del objetivo final del Taller, la realización de 3 piezas: retrato de espacio, retrato de una persona y un auto-retrato. Las dos únicas "reglas del juego" que deben ser respetadas son la duración de las piezas ( 3 minutos máximo) y el tema: enlazar cada uno de los relatos con la experiencia personal de empoderamiento.

Discusión y reflexión grupal para identificar los primeros indicadores de empoderamiento en las trayectorias vitales de cada uno de los participantes. Entrega a cada uno de los participantes del libro de Mahmoud Reza, Obreros Trabajando: Lecciones Cinematográficas de Abbas Kiarostami (2013). En él se detalla la crónica de un taller cinematográfico impartido por el célebre cineasta iraní, cuya obra está estrechamente vinculada al aprendizaje ${ }^{3}$. Las tesis de Kiarostami sobre cómo transmitir emoción con las imágenes y no con las palabras, ilustradas en el planteamiento y dinámica de los cursos, dialogan con La hipótesis del cine de Bergala.

b) Sesión 2. La pedagogía de las imágenes. Aplicando las tesis de Alain Bergala estas sesiones deben plantearse como un encuentro con la poética de las imágenes a partir de múltiples fragmentos fílmicos para reflexionar y debatir sobre ellos. Los fragmentos escogidos están directa o indirectamente vinculados con las piezas que deberán realizar los participantes del taller. Los films escogidos (Diarios filmados de David Perlov [1973-1983], Walden (Diaries, notes and sketches) de Jonas Mekas [1969], Le filmeur de Alain Cavalier [2005], Beepie [1965] y The Long Holiday [2000] de Johan van der Keuken, Agatha y los lectores ilimitados de Marguerite Duras [Agatha et les lecteurs illimitées, 1981], Sans Soleil de Chris Marker [1983], 10 on Ten de Abbas Kiarostami [2004] y Des dels nostres barris. Desde nuestros barrios del Instituto de Bellvitge [Cine en curso 2014-2015]) tienen como hilo conductor la escritura fílmica del yo (Martín Gutiérrez; 2008), donde el director del film mediante una cámara (y despojado de cualquier otro 
recurso) o bien a través del collage y el reciclaje de films domésticos, retrata su entorno a partir de una mirada personal y singular.

Mediante el género del diario filmado, cada una de las películas sugiere distintas maneras para realizar un retrato fílmico de: un espacio, una persona y uno mismo. El objetivo de esta primera fase del taller es provocar el encuentro de los participantes con los fragmentos de estas películas, de una escritura alejada de muchos de los cánones clásicos de la narración cinematográfica. Los visionados deben utilizarse a lo largo de estas sesiones como una vía para que los participantes puedan tejer un lazo entre sus experiencias de empoderamiento y las posibles vías de expresión de éstas. Entendiendo el empoderamiento como una noción relacional y asimétrica (Fortunati, 2014), se pretende aflorar reflexiones individuales y colectivas que deriven de los visionados y establezcan un diálogo sobre las diferentes nociones de empoderamiento de acuerdo a la persona, el grupo o el contexto (Lawrence Jakobson, 2006).

El trabajo con fragmentos fílmicos, a pesar de que no reproduce la experiencia irremplazable de ver una película es una herramienta para conectar a los participantes del taller con la emoción de las imágenes (Aidelman \& Colell, 2014, p. 26). Durante estas sesiones de visionado es fundamental que los participantes aprendan a identificar el porqué les produce una determinada emoción algunas de las imágenes que observan y cómo reinterpretan la realidad dichas imágenes. Para ello, se establecieron preguntas de partida muy simples que podían dinamizar la conversación: 1) ¿Cómo presenta al cineasta al personaje? 2) ¿Hay algún indicio de la relación que se establece entre el cineasta y el sujeto filmado? 3) ¿Qué tipos de planos sugieren más cercanía e intimidad? 4) ¿Cómo se percibe el ritmo en el montaje? (5) ¿Cómo interacciona la voz con la imagen? Es fundamental partir de preguntas simples que puedan recibir respuestas concretas. Es necesario crear lugares contidiandos desde donde interpelar a las imágenes, dado que muchas veces puden parecer extrañas para participantes que no han tenido otras aproximaciones al cine de autor.

c) Sesión 3. Observar y retratar al "otro". La fotografía es un arte muy útil para la iniciación a la tarea de encuadrar la realidad. Ante una hoja de contactos con múltiples imágenes muy similares, el fotógrafo debe seleccionar aquella que exprima mejor la idea que quiere mostrar. La imagen fija facilita el proceso de "creación de un cuadro". En esta sesión se utilizan las imágenes de algunos fotógrafos para el aprendizaje del encuadre del "otro", tanto a personas desconocidas (Richard Kalvar [serie fotográfica de Roma 1978-1984]), populares (Eve Arnold [serie fotográfica con la actriz Joan Crawford]) o muy familiares (Elliot Erwitt [Madre e hija, 1953] y Johan van der Keuken [retratos de su esposa y su hermana presentes en el libro: The Lucid Eye: The Photographic Work 1953-2000, 2001]. Finalizado el debate sobre las imágenes se realiza un paso a la práctica y los participantes del taller se hacen fotografías entre ellos, tratando de singularizar a través del retrato algunos de los aspectos que han surgido a lo largo de las sesiones de trabajo en grupo.

d) Sesión 4. Escuchar el mundo. Una sonidista presenta algunos ejemplos de trabajo del sonido, tanto en su rol significativo como en la utilización de la voz en off de forma personal e imaginativa: Barry Lyndon (Stanley Kubrick, 1975) y En busca de los sonidos perdidos (Ainhoa y Aitor Gametxo, 2013). Se trata de desarrollar una reflexión sobre la potencialidad del sonido para conducir la emoción.

e) Sesión 5. El trabajo grupal alrededor de los proyectos individuales de cada uno de los participantes. Esta sesión se centra exclusivamente en el trabajo audiovisual de los distintos participantes. A partir de los primeros esbozos (pruebas de cámara, fotografías, notas, etc.), se realizan discusiones grupales sobre el enfoque adoptado para narrar las distintas experiencias de empoderamiento. Durante este proceso de creación los participantes están acompañados de un tutor audiovisual que les guía en las cuestiones técnicas y también de un pedagogo. Ambos ejercen de simples guías para que el participante pueda encontrar aquellas imágenes y sonidos que puedan expresar de la forma más fiel posible su vivencia con respecto el empoderamiento.

f) Sesión 6. Discusión grupal (filmada) entre los participantes del taller, antes del rodaje de las piezas. La sesión es conducida por un/a especialista en el campo del empoderamiento que les ayuda a reflexionar alrededor de las decisiones que van a tomar respecto la realización de las piezas. Esta sesión ayuda a establecer el vínculo entre las imágenes potenciales que ponen a debate y las propias experiencias de empoderamiento. 
Rodaje y Edición de las piezas. Acompañados del cineasta que imparte el taller los participantes del webdoc ruedan las piezas con las cámaras facilitadas por la propia investigación o los dispositivos que tengan a su alcance. Durante el proceso de rodaje la figura del tutor funciona a modo de apoyo para dudas conceptuales y técnicas. El participante escoge el emplazamiento de cámara, el ángulo y todas las particularidades creativas de las que depende el plano.

g) Sesión 7. Discusión grupal (filmada) alrededor de las piezas finalizadas. A partir de su proyección ante los distintos participantes del proyecto se emprenden una serie de discusiones para analizar e interpretar las imágenes $y$, a partir de ellas, reflexionar sobre temas más genéricos vinculados con el empoderamiento juvenil como: la religión, la familia, el sexo, la inmigración o el futuro.

h) Sesión 8. Compartir las experiencias de empoderamiento. Proyección de las piezas finalizadas a los expertos en el ámbito del empoderamiento, representantes de la academia, las políticas de juventud y las asociaciones que trabajan con los jóvenes. Discusión grupal (filmada) alrededor de las piezas reflexionando sobre el proceso de empoderamiento experimentado por los participantes del taller, sobre el contenido de las piezas como indicadores de empoderamiento y sobre la posibilidad de trasladar estas experiencias a la sociedad. A partir de una serie de cuestiones planteadas por un especialista, los participantes se interrogan sobre el proceso de creación que ha hecho emergir la conciencia de empoderamiento.

Concluida esta última sesión, se realizaría una proyección final de las piezas con la asistencia de familiares y amigos de los participantes del webdoc HEBE - también con expertos en el ámbito de la pedagogía y las políticas de juventud-, que serviría de cierre del proceso.

\subsection{Fase 2: Diseño de la arquitectura del webdoc}

La estructura y diseño de navegación del webdoc HEBE responde a cuatro condiciones incluidas en el proyecto (marco) de investigación: 1) los recorridos interactivos realizados por el usuario del webdoc deben permitir la comparativa entre las distintas visiones de los participantes del taller de creación audiovisual acerca de los espacios, momentos y procesos de empoderamiento; 2) el usuario debe poder recorrer las experiencias de empoderamiento de un único participante del taller, para poder construir su relato de vida a partir del diálogo entre las piezas; 3) el usuario debe poder seguir el proceso creativo realizado a lo largo del taller a través de la posibilidad de interactuar/ visionar los comentarios de los participantes sobre el proceso de aprendizaje $y$, finalmente, las discusiones grupales alrededor de las piezas; 4) el usuario debe poder incorporar sus propias experiencias de empoderamiento a través de imágenes filmadas con sus dispositivos móviles. La arquitectura básica de materiales del webdoc puede resumirse de la siguiente manera (ver fig. 1).

\section{Estructura narrativa webdoc Proyecto HEBE}

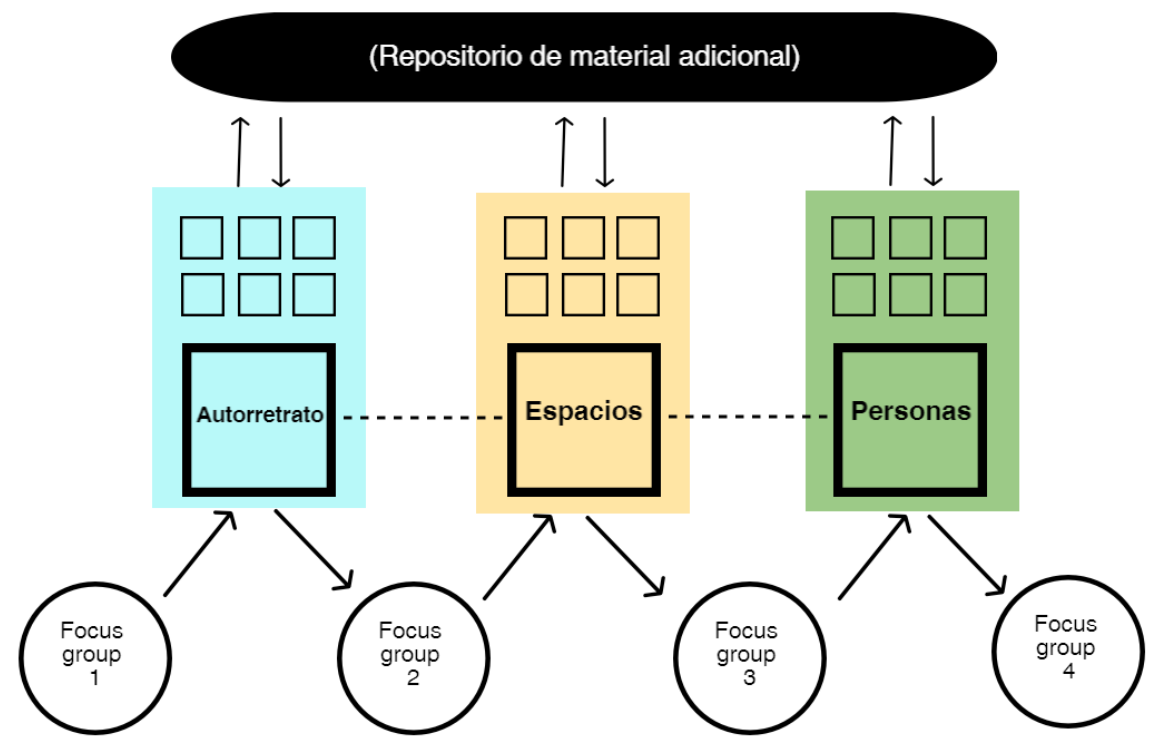


Este diseño responde a las dimensiones del empoderamiento relacional (Rusell et al. 2009) o interpersonal (Wong, 2008), en tanto que está concebido para hacer circular de manera nodal diferentes modos de empoderamiento juvenil, tanto por parte de los participantes en el documental como de los usuarios.

\subsection{Fase 3: Difusión del WEBDOC-HEBE}

La realización del webdoc no debe entenderse como un fin en sí mismo sino que debe ser el punto de partida para la incorporación de la ciencia ciudadana en la investigación. Por este motivo, por un lado, se establecerán una serie de estrategias de intervención en las redes sociales (twitter y facebook) para incentivar la participación de la ciudadanía en la creación audiovisual de sus propias experiencias de empoderamiento; por otro lado, se realizarán presentaciones del webdoc en distintas asociaciones y centros públicos que trabajan con la juventud (y que también están involucradas en el proyecto de investigación, como Consejo Asesor) con la finalidad de presentar la experiencia interactiva que ofrece el webdoc y así invitar a los jóvenes al diálogo y contraposición de puntos de vista sobre el empoderamiento.

\section{Resultados}

En esta fase final del proceso de creación del webdoc, las piezas realizadas por los participantes (consultables en: www.hebewebdoc.com) aportan un resultado relevante en cuanto a la tematización de los aspectos que plantean en los vídeos y su relación con el concepto de empoderamiento. Una primera valoración que podemos realizar del proyecto es desde una perspectiva cualitativa, tomando como centro de reflexión las piezas audiovisuales resultantes del taller. El retrato de personaje y el auto-retrato fílmico demuestran cómo la familia desempeña un rol esencial en la mayoría de participantes de la metodología HEBE. Es relevante el hecho que la joven de mayor edad sea la única que no sitúe a ningún personaje familiar en sus relatos de empoderamiento. Es evidente, pues, que tanto en las piezas como en las discusiones del focus group uno de los principales indicadores de empoderamiento que se muestran es la familia. Cabría considerar si este hecho deriva especialmente de la joven trayectoria vital de los participantes y de elementos socio-culturales propios del contexto español que sitúan a la familia en el centro de las relaciones interpersonales, de relación, desarrollo y formación. Por otra parte, la persona de referencia para el empoderamiento personal y la educación emocional de los participantes se erige más bien como un mentor que como un ejemplo sobre el cual los jóvenes quieran edificar una trayectoria personal o profesional a semejanza. Generalmente, las piezas referidas a estas personas se presentan a modo de homenaje y agradecimiento a una formación que va más allá de la definición que se ha dado de empoderamiento. Se puede deducir, de este modo, que existe un vínculo de deuda vital entre los protagonistas de HEBE y las personas que para ellos han sido empoderadoras. No señalan, a través de los relatos, un elemento substancial que permita explicar por qué y en qué les ha empoderado. Sin embargo, sí que se entiende que hay un componente global, que no obedece a ninguna característica o momento preciso, sino que se circunscribe en el contexto de un proceso continuo de acompañamiento y presencia constante en el crecimiento personal.

También en esa línea procesual, el auto-retrato se describe generalmente como una exploración biográfica que deriva en un análisis de carácter personal e identitario. Predominan los retratos íntimos, de alta profundidad en la indagación personal de las características de los participantes a través de sus orígenes. Por ello aparecen, a menudo, imágenes de archivo de los protagonistas, recorriendo sus experiencias infantiles, contrastadas con el momento actual. Además, surge un diálogo con la propia imagen y el físico, dando a esa exploración corpórea una dimensión muy concreta de la concepción del yo, combinada con reflexiones más abstractas y globales. Esta deriva hace pensar en que el componente procesual y temporal del empoderamiento se convierte en un elemento radicalmente vertebrador a la hora de auto-interpretarse bajo el prisma del empoderamiento. De hecho, entre los indicadores trabajados en el proyecto, aparecen los procesos capacitadores como un indicio definidor del empoderamiento. La concreción del ejercicio de exploración sobre el yo ratifica que cualquier cuestionamiento sobre la capacitación personal pasa por el análisis longitudinal de múltiples momentos y la recolección de esas experiencias bajo su percepción personal.

El visionado de estas piezas de auto-retrato por parte de los participantes rompe la empatía acrítica que podría tener el relato y les permite reflexionar desde sus propias historias con una enorme distancia, a partir de una posición de otredad que posibilita un contraste revelador de las propias contradicciones de los protagonistas a la hora de reflexionar sobre ellos mismos y su empoderamiento. Finalmente, en lo que se refiere al espacio, aparecen de manera indistinta lugares de formación, de residencia, de convivencia y de desarrollo laboral y profesional. A pesar de que 
está claro que los participantes no represetan una muestra significativa para objetivar datos, el estudio de caso confirma una tendencia a destacar aquellos espacios institucionalizados y de carácter formal, en detrimento de los lugares ocupados por los jóvenes de manera más espontánea, no controlada o con un componente absolutamente lúdico. De manera reveladora, los espacios vuelven a posarse sobre el tiempo: los lugares elegidos son espacios que significan o han significado algo para los protagonistas, a parte de por razones emocionales, por su ubicación cronológica y su extensión y prolongación. Su pregnancia radica no sólo en el carácter capacitador del espacio, sino también en el diálogo que ese espacio ofrece con el momento presente.

Por otra parte, el indicador de lugar se relaciona de manera directa con aspectos como la libertad, el refugio, la superación, la proyección profesional o la amistad. En cualquier caso, los tres elementos explorados definen un itinerario cronológico que hace pensar, de nuevo, que el vector tiempo es substancial en la definición del empoderamiento, porque permite trazar una línea de progresión del sujeto y un diálogo de mejora y comparación con el presente. El carácter evocativo y retrospectivo que ha supuesto esta indagación personal de los participantes puede tener que ver en este hecho, pero incluso cuando el ejercicio del taller pedagógico se ha planteado en términos de proyección futura ha aparecido la experiencia del pasado como elemento esencial para reflexionar sobre el empoderamiento personal.

\section{Discusión y conclusiones}

Como hemos apuntado con anterioridad, los resultados de este estudio de caso no pueden concretarse de manera definitiva en este artículo debido a que se encuentra en su fase final de implementación en la web. En cualquier caso, sí que podemos apuntar que el reciente formato audiovisual del webdoc, todavía en fase de desarrollo y experimentación debido a su juventud, permite una articulación colectiva de los relatos individuales de empoderamiento que aúna lo íntimo y personal con experiencias universales de los usuarios.
En ese sentido, el proyecto augura un valor destacable en tres vertientes. La primera de ellas hace referencia a la concreción del concepto de empoderamiento juvenil a partir del razonamiento meramente empírico de los participantes en el documental web. A él le acompañarán las acepciones de diversos expertos, como contraste o compleción a lo expresado por los protagonistas del documental.

En su segunda vertiente, el proyecto reflejará diferentes procesos de empoderamiento juvenil, que podrán explorarse como estudio de caso para concretar todo aquello que refiere al ámbito estudiado. La participación ciudadana, a través de la intervención en el webdoc, sobre dicho estudio se establecerá como un mecanismo para ahondar en el término de manera colectiva y bajo una aproximación absolutamente experiencial.

Finalmente, el proceso que lleva al documental, con las sesiones de preparación, seguimiento y grabación, devendrá un mecanismo de empoderamiento en sí mismo, de modo que la experiencia podrá entenderse como una metodología escalable y/o replicable para trabajar modelos aplicativos de empoderamiento en otro contexto.

Más allá de estos resultados previsibles, el proyecto quiere ahondar en fórmulas reproducibles para la aplicación de políticas de empoderamiento juvenil. A través del taller participativo propuesto, en el marco del Proyecto-HEBE, propone metodologías para la toma de conciencia del desarrollo personal entre los jóvenes y, al mismo tiempo, para la adquisición de una mayor capacitación intelectual y emocional a través del trabajo individual y colectivo del lenguaje y las artes visuales.

Se plantea, como alternativa de mejora, la introducción de otros ejercicios de exploración por parte de los participantes, los cuales puedan contribuir a definir con más concreción el concepto de empoderamiento. El resultado de las piezas audiovisuales realizadas por los jóvenes se asume generalmente desde una perspectiva esencialmente poética, incluso metafórica. Quizá el ejercicio de concreción que sí se ofrece en los focus group debería desarrollarse a la hora de ejecutar determinadas piezas o completar la abstracción de los vídeos producidos por los participantes con datos más concretos referidos al término que aquí se invoca. 


\section{Referencias bibliográficas}

Aidelman, N., \& Colell, L. (2014). Elogio del amor. Cine en curso. Cinema Comparat/ive Cinema. vol. 2, n. 5, 24-30.

Bergala, A. (2007). La hipótesis del cine. Pequeño tratado sobre la transmisión del cine. Barcelona: Laertes.

Bergala, A. (2014). Compartir los gestos de creación. Cinema Comparat/ive Cinema. vol. 2, n. 5, 12-17.

Betancor, M. (2011). “Empoderamiento: ¿̇una alternativa emancipatoria? Reflexiones para una aproximación crítica a la noción de empoderamiento". Revista Margen 61.

Casacuberta, D. (2009). Creación colectiva. En internet el creador es el público. Barcelona: Gedisa.Català, J. M. (2010). La necesaria impureza del nuevo documental. Líbero, vol. 13, n. 25. Brasil: Sao Paulo, 45-56.

Cohen, A.E. (2016). Investigación evaluativa para el diseño de una propuesta de intervención en edu-comunicación para la ciudadanía activa: análisis de los proyectos La Cruilla Comuna y Desmuntamites. Barcelona: Tesis doctoral dirigida por la Dra. Mónica Figueras y presentada en la UPF.

Comolli, J. (2007). Ver y poder. La inocencia perdida: cine, televisión, ficción, documental. Buenos Aires: Nueva Librería.

Delgado, M. (2015). Urban Youth and Photovoice. Oxford: Oxford University Press.

Finholdt, N., Michael, Y., \& Davis, M. (2010). Photovoice engages rural youth in childhood obesity prevention. Public Health Nursing, vol. 28, 186-192.

Fortunati, L. (2014). Media Between Power and Empowerment: Can We Resolve This Dilemma? The Information Society. 30 (3), 169-183.

Foster-Fishman, P., Law, K., Lichty, L., \& Aoun, C. (2010). Youth ReACT for social change: A method for youth participatory action research. Journal of Community Psychology, vol. 46, 67-83.

Gifreu, A. (2014). El documental interactivo como nuevo género audiovisual. Evolución, caracterización y perspectivas de desarrollo. Barcelona: UOC Press.

Haynes, K., \& Tanner, T. (2013). Empowering young people and strengthening resilience: youth-centred participatory video as a tool for climate change adaptation and disaster risk reduction. Children's Geographies, vol. 13, 357-371. DOI: 10.1080/14733285.2013.848599.

Irwin, A. (1995). Citizen science. A Study of People, Expertise and Sustainable Development. Nueva York: Routledge.

Ito, M. et al. (2010) Hanging Out, Messing Around, and Geeking Out. Kids Living and Learning with New Media. Cambridge (Massachusetts): The MIT Press.

Jenkins, H. (1992). Textual Poachers. Television Fans \& Participatory Culture. Nueva York: Routledge.

Jenkins, H., Ito, M., \& boyd, d. (2016). Participatory Culture in a Networked Era. Malden (USA): Polity Press.

Langlois, H. (1986). Henri Langlois. Trois cent ans de cinéma. Écrits. París: Cahiers du cinéma, Cinémathèque Française, FEMIS, pp. 96-99.

Lawrencejacobson, A. R. (2006). Intergenerational Community Action and Youth Empowerment. Journal of Intergenerational Relationships, 4 (1), 137-147.

Lloret, N., \& Canet, F. (2008) Nuevos escenarios, nuevas formas de expresión narrativa: La Web 2.0 y el lenguaje audiovisual. Hipertext.net, 6. En http://www.hipertext.net Última consulta: 26 de febrero de 2017.

Nichols, B. (1991). La representación de la realidad. Cuestiones y conceptos sobre el documental, Barcelona, Paidós.

Martin Gutiérrez, G. (Coord.) (2008). Cineastas frente al espejo, Madrid: T\&B Editores, pp. 3552.

Ohmer, M., \& Owens, J. (2013). Using Photovoice to Empower Youth and Adults to Prevent Crime. Journal of Community Practice, v. 21, issue 4, 410-433.

Pritzker, S., LaChapelle, A., \& Tatum, J. (2012). Urban Youth and Photovoice: Visual Ethnography in Action. Oxford: Oxford University Press.

Reips, U., \& Bosnjak, M. (2011). Dimensions of Internet Science. Lengerich (Alemania): Pabst Science Publishers.

Reflect-Action (2009). Reflect. Recuperado de http://www.reflect-action.org/es/home Última consulta: 26 de febrero de 2017.

Reza, M. (2013). Obreros Trabajando: Lecciones Cinematográficas de Abbas Kiarostami. Mhughes Press.

Russell, S. T., Muraco, A., Subramaniam, A., \& Laub, C. (2009). Youth empowerment and high school gay-straight alliances. Journal of youth and adolescence, 38, 891-903. doi:10.1007/s10964-008-9382-8

Scolari, C. A. (2013). Narrativas Transmedia: cuando todos los medios cuentan. Barcelona: Deusto Ediciones.

Sora, C. (2015). Etapas, factores de transformación y modelo de análisis del nuevo audiovisual interactivo online. El profesional de la información, 24 (4), 424-431. doi: 10.3145/epi.2015.jul.o9

Soler, P, Trilla, J., Úcar, X., \& Jiménez-Morales, M. (2017). La construcción de un modelo pedagógico del empoderamiento juvenil: espacios, momentos y procesos. Pedagogía Social. Revista Interuniversitaria, vol. 30.

Strack, R., Magill, C., \& McDonagh, K. (2004). Engaging youth through Photovoice. Health Promotion Practice, vol. 5, 49-58.

Streng, J.M., Rhodes, S., Ayala, G., Eng, E., Arceo, R. \& Phipps, S. (2004). Realidad Latina: Latino adolescents, their school, and a university use Photovoice to examine and address the influence of immigration. Journal of Interprofessional Care, 18 (4), 403-415. 
Tromp, M. (2007). A system of empowerment indicators for a corporate work environment. Johannesburg: University of Johannesburg. En http://152.106.6.200/handle/10210/737. Última consulta: 26 de febrero de 2017.

Van der Keuken, J. (2001). The Lucid Eye: The Photographic Work 1953-2000. Amsterdam: De Verbeelding.

Wagg, H. (2004). Empowering Youth With Radio Power: "Anything Goes" on CKUT Campus-Community Radio. Journal of Radio Studies, vol. 11:2, 268-276. doi: 10.1207/s15506843jrs1102_11.

Wang, C., \& Burris, M.A. (1997). Photovoice. Concept, methodology, and use for participatory needs assessment. Health Education \& Behavior, 24, 369-387.

Wang, C. (2006). Youth participation in photovoice as a strategy for community change. Journal of Community Practice, 14 (1-2), 147-161. doi:10.1300/J125v14nOI_09.

Wang, C., Morrel-Samuels, S., Hutchison, P. M., Bell, L. \& Pestrong, R. M. (2004). Flint Photovoice: Community building among youths, adults, and policymakers. American Journal of Public Health, vol. 94, 911-913.

Wilson, N., Dasho, S., Martin, A., Wallerstein, N., Wang, C., \& Minkler, M. (2007) Engaging young adolescents in social action through Photovoice: The Youth Empowerment Strategies (YES!) Project. Journal of Early Adolescence, vol. 27, 241-261.

Wong, N. (2008). A participatory youth empowerment model and qualitative analysis of student voices on power and violence prevention. A dissertation submitted in partial fulfillment of the requirements for the degree of Doctor of Philosophy (Health Behavior and Health Education). Michigan: University of Michigan. Retrieved from http://goo.gl/ yZLBrw. Last visit: 26th February 2017.

\section{Notas}

1 Para tener más información sobre el proyecto de Cine en Curso recomendamos consultar: http://www.abaoaqu.org/ es [última consulta 26 de febrero de 2017].

2 Para tener más información sobre el proyecto YouthME recomendamos consultar: http://youthme.eu/ [última consulta 26 de febrero de 2017].

3 El hecho de que Kiarostami inicie su andadura cinematográfica en 1970 en el "Centro para el Desarrollo Intelectual de Niños y Adolescentes" (conocido como "Kanun") es fundamental para comprender el didactismo que emana de la mayor parte de su obra. Dicha institución no sólo se convierte, para él, en un reducto de libertad creativa dentro del contexto político de Irán, sino que además le permite explorar las posibilidades del medio cinematográfico al que se acerca por primera vez. Antes había trabajado en el campo de la publicidad y el diseño gráfico, pero nunca en el del cine. Su azarosa e inesperada entrada en el Kanun significa un doble proceso de aprendizaje: el de la persona autodidacta que aprende el cine a través de hacer cine y el de los niños, protagonistas de la mayoría de sus trabajos, que aprenden a través del cine y de su participación en él como principales actores. Este trabajo en el seno de la Institución no debe entenderse exclusivamente como la realización de cine para niños, sino más bien en una puesta en marcha de una "educación para mirar el mundo" que será el eje central de su obra.

\section{CÓMO CITAR ESTE ARTÍ́CULO}

Salvadó, A., Jiménez-Morales, M., \& Sourdis, C. (2017). El género del documental interactivo como experiencia artística-creativa de empoderamiento juvenil: el caso del Webdoc Hebe. Pedagogía Social. Revista Interuniversitaria, 30, 95-109. DOI: 10.7179/PSRI_2017.30.07. 


\section{DIRECCIÓN COMPLETA DE LOS AUTORES}

Alan Salvadó: Universitat Pompeu Fabra, Carrer Roc Boronat, 138, 08018-Barcelona. alan.salvado@upf.edu

Manel Jiménez: Universitat Pompeu Fabra, Carrer Roc Boronat, 138, 08018-Barcelona. manel.jimenez@upf.edu

Carolina Sourdis: Universitat Pompeu Fabra, Carrer Roc Boronat, 138, 08018-Barcelona. csourdisa@gmail.com

\section{PERFIL ACADÉMICO}

Alan Salvadó: Profesor de la Universitat Pompeu Fabra en el Departamento de Comunicación y miembro del Grupo de Investigación CINEMA cuya principal línea de trabajo son las nuevas tendencias del cine europeo contemporáneo. Su tesis y sus principales líneas de investigación giran alrededor de las representaciones del paisaje en el cine. Actualmente es colaborador del Grupo de investigación CRECI de la Université de Paris III, Sorbonne Nouvelle, y coordinador del Máster Internacional en Estudios Cinematográficos organizado en colaboración con distintas universidades europeas.

Manel Jiménez: Licenciado en Comunicación audiovisual por la Universitat Pompeu Fabra y en Teoría de la literatura y Literatura comparada por la Universitat de Barcelona. Doctorado en Comunicación social por la Universitat Pompeu Fabra. Ha sido guionista, productor y realizador de varios proyectos audiovisuales, así como de programas culturales (Via Digital, Ona Catalana, Ràdio Barcelona/La SER). Contribuye, desde el ensayo y la crítica, en varias publicaciones y editoriales. Ha contribuido en varios estudios a nivel individual y dentro de los grupos de investigación en comunicación UNICA y CINEMA. Cuenta con tres estancias de investigación (University of Oxford, University of California Los Angeles y British Film Institute) y ha impartido docencia en diversas universidades alemanas.

Carolina Sourdis: Realizadora e investigadora audiovisual formada en Bogotá y Barcelona. Sus trabajos audiovisuales han sido exhibidos en festivales internacionales en España, Colombia e Irán. Como investigadora ha trabajado sobre el montaje y las prácticas del found footage apoyada por el Ministerio de Cultura de Colombia. Es investigadora predoctoral en el departamento de comunicación de la Universitat Pompeu Fabra. Sus líneas de investigación son las derivas ensayísticas en el cine europeo y los puntos de convergencia entre práctica y teoría cinematográfica. 
